\title{
Protestantes, evangélicos y pentecostales: aclaraciones conceptuales preliminares en un campo de investigación social
}

\author{
Protestants, Evangelicals and Pentecostals - Some \\ preliminary conceptual clarifications in a social \\ research field
}

\author{
Fernando García Leguizamón ${ }^{1}$
}

\section{Resumen}

En este artículo se exponen, inicialmente, los principios doctrinales básicos del protestantismo y, dentro de este, se describen el origen y las características del pentecostalismo, el movimiento religioso de mayor crecimiento en la actualidad a nivel mundial. Posteriormente, se bosquejan aspectos históricos del arribo y desarrollo de estas dos corrientes en Colombia. Finalmente, se presentan algunos elementos teóricos de su abordaje en la sociología y en la psicología contemporáneas.

\section{Palabras clave}

Protestantismo, evangelicalismo, pentecostalismo, sociología de la religión, psicología del pentecostalismo.

\section{Abstract}

This paper sets out the basic doctrinal principles of Protestantism and points out the rise and core traits of the currently fastest growing religious movement in the world, which is Pentecostalism. Subsequently, it outlines the historical aspects of the arrival and development of protestant churches in Colombia and finally, it introduces some theoretical approaches in order to address these religious phenomena in contemporary sociology and psychology.

Key words:

Protestantism, Evangelicalism, Pentecostalism, religion sociology, Pentecostalism psychology.

Artículo recibido el 20 de marzo de 2012 y aprobado el 19 de julio de 2012

1 Docente investigador del programa de Psicología de la Universidad Piloto de Colombia, Bogotá Colombia. Correo electrónico: fernando-garcia@unipiloto.edu.co 
Los eruditos tienen sus supersticiones y entre ellas sobresale la creencia de que la superstición se está desvaneciendo. (Garry Wills, 1990)

La seguridad autoafirmante de la racionalidad moderna hizo augurar, desde el siglo XIX, que la religión perdería paulatinamente su influjo sobre la sociedad y la cultura. Ya si se la consideraba como algo superfluo o como obstáculo del progreso, su desaparición resultaría espontáneamente de la difusión de la ciencia o se establecería como objetivo programático. En 1844, Marx afirmó que "la eliminación de la religión como ilusoria felicidad del pueblo, es la condición para su felicidad real". (1968, p. 8). Bajo relaciones sociales distintas a las propias de sociedades estructuralmente desiguales, la promesa de felicidad en un más allá se haría innecesaria: "El estímulo para disipar las ilusiones de la propia condición, es el impulso que ha de eliminar un estado que tiene necesidad de las ilusiones. La crítica de la religión, por lo tanto, significa en germen, la crítica del valle de lágrimas del cual la religión es el reflejo sagrado". (p. 9). También Freud (1927) describió la religión como una ilusión, producto de un sentimiento infantil de indefensión proyectado en la imagen un padre todopoderoso; con el progreso de las ciencias que permiten la aceptación humana de dicha impotencia, tal sentimiento desaparecería. Cuarenta años más tarde, el antropólogo Anthony Wallace (1966) sentenció en un tono similar que el destino evolutivo de la religión era su extinción: "La creencia en seres y fuerzas sobrenaturales que afectan a la naturaleza sin someterse a sus leyes se deteriorará hasta llegar a convertirse en un interesante recuerdo histórico [...] La creencia en poderes sobrenaturales está condenada a desvanecerse, en todo el mundo, como consecuencia de la creciente difusión del conocimiento científico". (p. 265). Al mismo tiempo, el sociólogo Peter Berger (1967) constataba que el mundo occidental moderno produce cada vez más individuos que miran el mundo y sus propias vidas sin el beneficio de las interpretaciones religiosas. Recientemente, el conocido biólogo Richard Dawkins (2006), ateo militante en lucha ilustrada contra la religión, la ha calificado de nuevo como una ilusión o, más exactamente, como delusion, esto es, una creencia falsa que se mantiene a pesar de las evidencias en contra, anotando con mordacidad que "cuando una persona padece de un delirio se habla de locura; cuando son muchas personas las que lo padecen, se habla de religión" (p. 5).

Sin embargo, la aspereza de la crítica de Dawkins es prueba de que esta delusion no es menos persistente en la actualidad. A pesar de que el creciente cuestionamiento de las explicaciones religiosas sobre la naturaleza, la historia y la cultura llevó a pronosticar el declive o, al menos, el confinamiento de la religión a los discretos espacios de la vida privada, el final del siglo XX presenció una nueva explosión de lo religioso, que llevó a un defensor de la racionalidad como Habermas (2005) a señalar el surgimiento de una "sociedad postsecular" con nuevos rasgos en su esfera pública, y al mismo Berger (1996) a reconocer que en la actualidad no vivimos ya una crisis de la religiosidad, sino una crisis del secularismo.

En qué medida la idea de un "retorno" de lo religioso puede generalizarse como fenómeno global, o si más bien describe la situación histórica específica de un sector del mundo occidental, mientras soslaya otras dinámicas regionales en las que nunca triunfó plenamente el secularismo y en las que lo que se manifiesta en la actualidad es una particular hibridación de elementos religiosos tradicionales y novedosos, es una pregunta a la que se enfrentan los estudios contemporáneos sobre difusión del pentecostalismo en América Latina, África y Asia (Bastian, 2006; Anderson, 1999; Alexander, 2009).

El fenómeno del crecimiento de las iglesias popularmente llamadas "evangélicas" o "cristianas" ha atraído en el último tiempo la atención de científicos sociales en nuestro país. Consideramos que este es un campo que tiene aún bastante por explorar y en el que bien puede pensarse en investigaciones interdisciplinares, capaces de aproximarse a la particular coalescencia de dimensiones culturales, sociales, políticas y económicas en torno a una vivencia religiosa, y a la manera en que los sujetos se producen a sí mismos y como creyentes construyen su realidad dentro de ellas. Un horizonte tal impone 
como primera tarea la construcción de un lenguaje común, a partir de la aclaración de elementos históricos, doctrinales y teóricos básicos sobre el protestantismo y su evolución en nuestro medio. El presente escrito tiene como propósito contribuir a esta comprensión preliminar. Es el producto de la primera etapa en una investigación que abordará la pregunta por la constitución de subjetividades religiosas en movimientos pentecostales en Colombia.

\section{El protestantismo}

El término "protestante" tiene su origen en la protesta formal presentada en 1529 por un pequeño grupo de príncipes alemanes, contra la disposición imperial que les impedía decidir autónomamente sobre la religión practicada en su territorio, y que buscaba de esa manera frenar la expansión del movimiento religioso inspirado en las ideas de Lutero. Es de esta forma que el término se relaciona con la Reforma, iniciada en 1517 en la ciudad alemana de Wittenberg con la publicación de las "Noventa y cinco tesis" de Lutero, una serie de cuestionamientos dirigidos fundamentalmente a la manera en que la Iglesia Católica administraba la salvación. Aunque no era la intención de Lutero crear una división dentro de la Iglesia Católica, sus tesis desataron una revolución religiosa y ocasionaron su excomunión en 1521. A los disidentes luteranos que apoyaban la Reforma se les llamó en adelante "protestantes" y ellos mismos adoptaron el calificativo, que se amplió además para denominar a las tres doctrinas cristianas no católicas que surgieron en el siglo XVI: luterana, calvinista y anglicana. Mientras que buena parte de las iglesias protestantes de inspiración luterana adoptarán de forma oficial la denominación de "evangélica" (que como veremos no debe confundirse con el movimiento "evangelical" surgido en los Estados Unidos a finales del siglo XIX), las iglesias fundamentadas en las doctrinas de Juan Calvino adoptan predominantemente el término de "reformada".

Los puntos fundamentales del protestantismo se suelen resumir en las llamadas "cuatro solas": sola scriptura, sola fide, sola gratia y solus Christus. Básicamente se afirma que no hay jerarquía entre los creyentes, de manera que nadie, excepto Cristo, pue- de mediar entre Dios y los hombres; que cualquier creyente puede llevar a cabo oficios religiosos (sacerdocio universal); que el celibato no es condición de santidad; que la comunión tiene un significado simbólico de integración de la comunidad en Cristo, pero que en ella no se realiza una transubstanciación; que la gracia (el don divino de la salvación dado a los pecadores) no se consigue por las buenas obras, únicamente por la fe; que la palabra de Dios se revela directamente a los creyentes en la escritura, a la que se le debe reconocer una suprema autoridad; y que ni clérigos, ni santos pueden ser objetos de una glorificación que solo corresponde a Dios.

El protestantismo elimina buena parte de los canales de mediación que unen al católico con la divinidad: el aparato sacramental queda reducido a un mínimo (solo se reconocen el bautismo y la comunión) y despojado de sus cualidades numinosas; la intercesión de los santos y la oración por los difuntos se hacen superfluas; la irrupción de lo "sobrenatural" en los milagros deja de ser significativa.

Como resume Berger (1973), el protestantismo se despoja de los tres elementos más antiguos y poderosos de lo sagrado: el misterio, el milagro y la magia; en ese sentido, contribuye al desencantamiento del mundo. El creyente deja de vivir en un mundo penetrado por seres y fuerzas sagradas y la realidad se polariza entre una divinidad radicalmente trascendente y una humanidad desprovista de cualidades sagradas; entre estos dos polos aparece el universo natural, creado por Dios, pero con un carácter inmanente. El protestantismo, puntualiza Berger (1973), “despojó al mundo del carácter divino con el propósito de enfatizar la terrible majestad del Dios trascendente y arrojó al hombre en su condición de "caído" para hacer que se abriera a la intervención de la soberana gracia divina, el único milagro verdadero en el universo protestante". (p. 117). En la doctrina calvinista se afirma, incluso, que el destino de los elegidos y de los condenados está decido desde el comienzo de los tiempos y que nada de lo que obre la persona en el mundo puede cambiar esa misteriosa decisión divina.

Esto permite entender por qué se suele considerar al protestantismo como una de las fuentes de la 
subjetividad moderna y cómo en él se encuentran los gérmenes de una comprensión racional (secular) de un mundo que se abre a la intervención de la ciencia y la tecnología. A esto se agrega, como sostuvo Weber (1969), una ética del trabajo diligente, la vida frugal y la disciplina del ahorro -especialmente dentro del calvinismo, donde la prosperidad económica aparece como signo indirecto de ser parte de los elegidos- que contribuyó al desarrollo del capitalismo.

\section{El evangelicalismo}

Una vez establecido el protestantismo en Europa, lo que solo ocurrió tras un período de cruentas guerras religiosas entre mediados de los siglos XVI y XVII, surgieron en su seno movimientos que deploraban el languidecimiento de la fe originaria, lo que veían como consecuencia de la formalización en la que habían caído las nuevas iglesias, y que entablaron una cruzada contra la rutinización y la ritualización mecánica, llamando a un despertar o reavivamiento de la vida piadosa.

Un primer Gran Despertar tuvo lugar en Europa y las colonias norteamericanas, aproximadamente entre 1720 y 1750 y condujo, dentro del luteranismo de Alemania y Escandinavia, al nacimiento del pietismo, mientras que en Inglaterra llevó al surgimiento de la Iglesia Metodista. El Segundo Gran Despertar se dio en Estados Unidos entre 1795 y 1835 y de allí se extendió a Inglaterra. A partir de entonces aparecieron "revivalistas" profesionales que viajaban por pueblos y ciudades, organizando encuentros anuales de reavivamiento por encargo de pastores locales interesados en el fortalecimiento de sus iglesias. El Tercer Gran Despertar tuvo lugar entre 1875 y 1915 y se dirigió, de una parte, a evangelizar las masas de obreros de las urbes industrializadas, y de otra, a hacer frente a la cada vez más difundida visión materialista de la naturaleza inspirada en la teoría de la evolución. Mientras el segundo reavivamiento es significativo para el surgimiento del movimiento evangelicalista, el tercero es la antesala a la consolidación del fundamentalismo.

Aunque el adjetivo "evangélico" había sido utilizado con frecuencia desde el siglo XVI para nombrar a los protestantes en general, hacia finales del siglo XIX el término empieza a designar en los Estados Unidos a un sector particular de protestantes que, además de afirmar su creencia en el Evangelio, de una parte se distancian enfáticamente de la teología liberal desmitologizante que permeaba por entonces a las iglesias protestantes, para defender, por el contrario, una interpretación literal de la Biblia a la que consideran como inspirada plenamente por la Divinidad y por tanto como texto fiel, infalible e incuestionable. De otra parte, se adhieren a una escatología premilenarista, opuesta a la comprensión histórica que animaba a los seguidores de un evangelio social, según el cual la salvación no está dada solo a los individuos, sino también a las sociedades pecaminosas mediante la corrección de sus instituciones injustas.

En el capítulo veinte del libro de la Revelación se menciona en un tiempo de paz y felicidad de mil años, el "reino de los justos" que se instaurará en la Tierra tras el triunfo divino sobre Satanás, después de que este haya gobernado durante siete años. Al cabo de esos mil años el Demonio será de nuevo desencadenado, volverá el mundo y tendrá lugar el Juicio Final. Durante el siglo XIX se impuso una interpretación de este pasaje, de acuerdo con la cual la segunda venida de Cristo tendría lugar después del milenio y que, entre tanto, la realización de ese reino de paz comprometía a los cristianos en un trabajo de reformas sociales a la luz de principios cristianos. El Segundo Gran Reavivamiento había despertado un optimismo no solo respecto a la posibilidad de una santificación individual, sino también sobre la perfectibilidad de la sociedad, lo que impulsó a numerosos creyentes (sobre todo en el norte del país) a que se adhirieran al movimiento abolicionista, a la lucha por una reforma carcelaria, a las demandas de oportunidades equitativas de estudio para las mujeres, así como a campañas contra el duelo y por la promoción de la temperancia (Balmer, 2004). Sin embargo, la guerra secesionista, la visible precarización que iban dejando los procesos de urbanización y de industrialización, y la masiva inmigración de grupos étnicos con creencias religiosas que poco fomentaban la temperancia, producen 
un panorama sombrío en el que el optimismo de un mundo mejor cede su lugar a la visión pesimista de una inminente decadencia. Eventos apocalípticos que para los protestantes habían tenido hasta entonces solo un significado histórico o alegórico, adquieren un carácter profético: el visible triunfo del mal anuncia el tiempo de la Gran Tribulación y la proximidad de la segunda venida de Cristo; los verdaderos cristianos serían "raptados" en una especie de ascensión, para regresar a disfrutar del reino milenario una vez que Dios hubiera destruido a los pecadores y acabado con el dominio del Anticristo en la Tierra. Esto representa la sustitución de una concepción postmilenarista de la historia universal por una premilenarista y tiene, por supuesto, consecuencias sobre las posibilidades y el sentido de la acción política en un mundo condenado del que había que alejarse para preservarse de la tentación y el pecado.

Para hacer frente a la difusión de ideas materialistas y liberales en los primeros decenios del siglo $\mathrm{XX}$, evangelicalistas conservadores publican entre 1915 y 1920 The Fundamentals, una colección de textos en los que se consigna la ortodoxia de lo que en adelante se conocerá como el fundamentalismo: la inerrancia bíblica, la concepción inmaculada, la redención y resurrección de Cristo, la autenticidad de los milagros y la interpretación premilenarista de la Biblia. Luego de reiteradas disputas y algunas derrotas jurídicas, los fundamentalistas se retiran en los años veinte de la vida pública, manteniendo su trabajo de adoctrinamiento en seminarios e institutos bíblicos, sociedades misionales y casas editoriales. Solo después de medio siglo se les verá reaparecer en el escenario político estadounidense (Balmer, 2004).

\section{El pentecostalismo}

John Wesley, fundador del movimiento metodista en Inglaterra hacia mediados del siglo XVIII, había sostenido que los rituales litúrgicos eran menos importantes que la experiencia individual de la conversión, en cuanto esta representa un acto consciente que acerca a la persona a Cristo y la hace objeto de su perdón. Pero la conversión era solo el comienzo del camino en una vida renacida que se debía orientar en adelante por su aspiración a la santidad -como crecimiento en el amor a Dios y a la humanidad. Tras la conversión habría una "segunda obra de gracia", por la cual el creyente se acerca el estado de purificación en el que se limpia de su inclinación a cometer pecado.

Esta doble aspiración -que está además en el espíritu de los dos primeros Grandes Despertaresanimará al llamado Movimiento de Santidad en Norteamérica durante la segunda mitad del siglo XIX. Dentro del metodismo empezó a distinguirse un ala de creyentes que asociaban este momento de purificación con un conjunto de dones recibidos del Espíritu Santo, que llegaban a considerar como un "tercer momento de gracia”. Al polarizarse las posiciones respecto a estas experiencias dentro de la Iglesia Metodista - para finales de siglo la denominación más numerosa en Norteamérica con aproximadamente cuatro millones de seguidores- unos cien mil adherentes del Movimiento de Santidad abandonaron el metodismo, para definir su identidad cristiana en torno a la búsqueda de esta bendición, que se empezó a identificar como un "bautismo de fuego", manifestado en forma de trances, habla en lenguas, danzas, "risa santa" y espasmos. Con esto se introducen en la práctica litúrgica elementos emotivos que habían estado excluidos de los cultos luteranos, calvinistas y anglicanos tradicionales. En adelante, tales prácticas dejarán de ser marginales para ocupar un lugar central en la ritualidad de un movimiento que alcanzará durante el siglo XX la mayor expansión que haya tenido cualquier denominación protestante: el pentecostalismo.

Según se narra en el libro de los Hechos, en el día de Pentecostés -el quincuagésimo día desde el inicio de la Pascua- estaban los apóstoles reunidos: "De repente vino del cielo un estruendo como de un viento recio que soplaba, el cual llenó toda la casa donde estaban sentados; y se les aparecieron lenguas repartidas, como de fuego [...] Y fueron todos llenos del Espíritu Santo, y comenzaron a hablar en otras lenguas, según el Espíritu les daba que hablasen" (Hechos 2: 2-4). Ante la sorpresa y 
las burlas de los habitantes de Jerusalén, Pedro les increpa, recordando las palabras del profeta Joel:

Y en los postreros días, dice Dios, derramaré de mi Espíritu sobre toda carne, y vuestros hijos y vuestras hijas profetizarán; vuestros jóvenes verán visiones, y vuestros ancianos soñarán sueños; y de cierto sobre mis siervos y sobre mis siervas en aquellos días derramaré de mi Espíritu, y profetizarán. Y daré prodigios arriba en el cielo, y señales abajo en la tierra, sangre y fuego y vapor de humo; el sol se convertirá en tinieblas, y la luna en sangre, antes que venga el día del Señor, grande y manifiesto; $y$ todo aquel que invocare el nombre del Señor, será salvo. (Hechos 2: 17-21)

Este pasaje, que no había recibido especial atención de parte de católicos y protestantes, adquiere una singular relevancia a principios del siglo XX en algunos sectores del Movimiento de Santidad. En Topeka, Kansas, el predicador Charles F. Parham, quien había abandonado la Iglesia Metodista en 1895 criticándola por haber caído en un frío formalismo que impedía predicar la palabra de Dios a partir de la inspiración directa, exhortaba a sus discípulos a buscar, por medio de la oración y el estudio de la Biblia, el derramamiento revitalizante del Espíritu Santo. Cuenta la historia que el $1^{\circ}$ de enero de 1901 sus discípulos recibieron el bautismo esperado y empezaron a hablar en una lengua desconocida, lo que interpretaron como señal de que estaban viviendo los últimos días antes de la segunda venida de Cristo. A partir de entonces emprendieron una intensa campaña de evangelización en el suroccidente norteamericano, que cinco años después los llevó a los suburbios de Los Angeles. Bajo la guía del pastor afroamericano William Seymour, se abrió en Azusa Street una iglesia que ganó pronto una inmensa fama y se constituyó en el epicentro desde el que se diseminó, directa o indirectamente, el movimiento pentecostal hacia todo el país y pronto al mundo (Koester, s.f). En América Latina se identifica ya en 1910 la presencia pentecostal dentro de una Sociedad Metodista de la ciudad de Valparaíso, en Chile. Poco después, en 1914, se pueden encontrar misiones pentecostales en el nordeste de Brasil y el noroeste de México
(Bastian, 2006). A Colombia arriba el primer misionero pentecostal en 1931, un norteamericano llamado Charles Berchtold, quien se establece en la región de Santander (Hernández y Forero, 2005).

A los dones iniciales del habla en lenguas (glosolalia) y de la profecía como signos del bautizo del Espíritu Santo, se agregan pronto las prácticas de sanidad (taumaturgia) y la liberación de demonios (exorcismo). En cuanto a su interpretación bíblica, los pentecostales son literalistas, creen en la inerrancia de la Escritura y defienden una escatología premilenarista. Aunque estas creencias se difundieron inicialmente entre las clases bajas de la sociedad norteamericana, después de la Segunda Guerra Mundial empezaron a ascender en la escala social y económica de ese país. Hacia mediados de los años cincuenta, un pastor pentecostal llamado Oral Roberts empezó a hacer uso de la televisión, lo que le permitió alcanzar una gran difusión para sus mensajes, no solo dentro de las diferentes denominaciones protestantes, sino también en sectores de la Iglesia Católica. A comienzos de los años sesenta el espíritu pentecostal logra permear creencias y prácticas de buena parte de las denominaciones protestantes tradicionales, dando origen al llamado movimiento carismático (quienes reciben el don o la gracia, que es el significado de la palabra griega carisma). Poco después alcanzará también a la Iglesia Católica dando origen al movimiento de Renovación Católica Carismática, favorecido por el espíritu de apertura promovido por el Concilio Vaticano II (Schäfer, 1992).

En el caso de América Latina, a pesar de los tempranos asentamientos, el pentecostalismo se mantendrá prácticamente desapercibido hasta los años cincuenta, restringido a "poblaciones marginadas y analfabetas, a sectores sociales oprimidos, ignorados por la élites sociales y las vanguardias ideológicas liberales y protestantes". (Bastian, 2006, p. 45). Su expansión se inicia en los años sesenta, gracias a las campañas de evangelización y a la utilización de la radio para la emisión de mensajes como los de Luis Palau y el Hermano Pablo, que llegaban a toda América. 
En poco más de un siglo de existencia, el pentecostalismo ha mostrado un crecimiento sin parangón en la historia de los movimientos religiosos: si en 1901 todo había iniciado con 40 creyentes, en 1945 se contaban ya 16 millones y en 1975, 96 millones de seguidores en el planeta (Barrett, 1982). Aunque no se dispone de cifras exactas debido a que no siempre es clara la manera en que se contabiliza a los miembros de iglesias pentecostales o de comunidades carismáticas con respecto a los feligreses de las demás iglesias evangélicas, a mediados de los noventa Synan (1997) calculó que había aproximadamente 217 millones de "pentecostales denominacionales", que junto con los miembros de comunidades carismáticas sumarían aproximadamente 465 millones, constituyendo la familia de cristianos más grande del mundo, después de la católica romana. En 2007 el cardenal Walter Kasper estimó aproximadamente 400 millones de pentecostales y unos 200 millones de carismáticos. A partir de una estimación de 54 mil conversiones por día y de 19 millones por año, Barrett (1988, citado por Koester, s.f.) proyectó que para el año 2025 serán en el mundo 740 millones.

África y América Latina son los espacios geográficos con mayor expansión del pentecostalismo. Aproximadamente el 85\% de los evangélicos latinoamericanos son pentecostales, de manera que su crecimiento específico se puede inferir a partir de las cifras globales del aumento de la población evangélica. Stoll (1993, basándose en Johnstone, 1986), sostiene que entre 1960 y 1985 la población evangélica se duplicó en Chile, Paraguay, Venezuela, Panamá y Haití; triplicó su proporción con respecto a la población total en Argentina, Nicaragua y República Dominicana; casi se cuadruplicó en Brasil y Puerto Rico; se quintuplicó en El Salvador, Costa Rica, Perú y Bolivia; se sextuplicó en Ecuador, Colombia y Honduras; y aumentó proporcionalmente siete veces en Guatemala. Recientemente se ha estimado que los cristianos evangélicos representan el 20\% de la población latinoamericana (BBC Mundo, 2007). En el caso de Colombia, se calcula que habría aproximadamente 5 millones (El Tiempo, 2011), lo que equivale aproximadamente a un nueve por ciento de la población. Las estadísticas nacionales no tienen, sin embargo, una base fiable, en tanto no se adelante un censo sistemático, una tarea que está a la orden del día para Cedecol, la organización que reúne a la mayor parte de las iglesias evangélicas en el país (Castaño, 2012).

\section{El arribo del protestantismo a Colombia}

Poco éxito tuvo la fe protestante para asentarse tempranamente en las colonias españolas, como no lo había tenido tampoco en España, que en el siglo XVI se había convertido en el bastión de la ortodoxia católica contrarreformista en Europa, al tiempo que se mantenía vigilante ante la penetración de herejías en sus colonias. La antigua institución de la Santa Inquisición se reorganizó para preservar la hegemonía de la fe católica en el Nuevo Mundo, persiguiendo con celo a los fieles de la herejía protestante que arribaban a estas tierras. Los tribunales de la Inquisición se establecieron en Lima en 1570 y en Cartagena de Indias en 1611. En el primer edicto del Tribunal de Cartagena se llama a los creyentes católicos a delatar a los seguidores de doctrinas proscritas: la Ley de Moisés, la secta de Mahoma y, especialmente, la secta de Lutero' ${ }^{1}$. Durante el siglo XVII se adelantaron aproximadamente veinte procesos por esta herejía específica, lográndose varias

1 Allí se advierte: “ 0 si sabéis o habéis oído decir que alguna ó algunas personas hayan dicho, tenido o creído que la falsa y dañada secta de Martín Lutero y sus secuaces es buena, ó hayan creído y aprobado algunas opiniones suyas, diciendo que no es necesario que se haga la confesión al sacerdote, que basta confesarse á sólo Dios, y que el Papa ni sacerdotes tienen poder para absolver los pecados, y que en la hostia consagrada no está el verdadero cuerpo de nuestro señor Jesucristo y que no se ha de rogar á los santos, y que no ha de haber imágenes en las iglesias, y que no hay purgatorio, y que no hay necesidad de rezar por los difuntos, y que no son necesarias las obras, que basta la fe con el bautismo para salvarse, y que cualquiera puede confesar y comulgar, uno á otro, debajo de entrambas especies, pan y vino, y que el Papa no tiene poder para dar indulgencias, perdones ni bulas, y que los clérigos, frailes y monjas se pueden casar; ó que hayan dicho que no ha de haber frailes ni monasterios, quitando las ceremonias de la religión, ó que hayan dicho que no ordenó ni instituyó Dios las religiones, y que mejor y más perfecto estado es el de los casados que el de la religión, ni el de los clérigos ni frailes, y que no hay fiestas más que los domingos, y que no es pecado comer carne los viernes, ni en cuaresmas ni en vigilias, porque no hay ningún día prohibido para ello; o que hayan tenido o creído alguna ó algunas otras opiniones del dicho Martín Lutero y sus secuaces, ó se hayan ido fuera destos reinos a ser Luteranos" (citado por De Bucana, 1995, p. 25). 
abjuraciones y una condena a la hoguera en 1622. En el siglo XVIII se registran ocho procesos más.

El Santo Oficio fue abolido por el Congreso de Cúcuta en 1823, pero es el antecedente que explica la ínfima difusión de la fe protestante en Colombia hasta mediados del siglo XIX. A partir de entonces se inicia un proceso de penetración del protestantismo, coincidente en sus rasgos generales con el que tuvo lugar en el resto de América Latina, y en el que se pueden identificar al menos cinco momentos u "oleadas" importantes (Moreno, 2010; Bastian, 2006):

La primera oleada la constituyen, de una parte, las confesiones de inmigrantes, principalmente británicos (comerciantes legionarios participantes en las campañas libertadoras), radicados en la naciente república. De otra parte, las Sociedades Bíblicas, que promovían un examen libre de la Escritura y que con el apoyo del gobierno crean en 1925 la primera Sociedad Bíblica en el territorio nacional. El pensamiento ilustrado y anticlerical de los precursores de la Independencia y de círculos políticos que apoyaban la separación entre Iglesia y Estado como condición de la libertad subjetiva, favoreció el asentamiento de estas primeras semillas del protestantismo y posibilitó lo que se puede considerar como la primera expresión de tolerancia religiosa en nuestro país (De Bucana, 1995).

Sin embargo, la libertad de culto no logra establecerse sólidamente, a pesar de que en ese mismo año Gran Bretaña la había puesto como condición para la firma de un tratado comercial con la Gran Colombia. La Constitución de 1830 resolverá finalmente que "es el deber del gobierno, en el ejercicio del patronato de la iglesia colombiana protegerla, y no tolerar el ejercicio público de ninguna otra" (citado por De Bucana, 1995, p. 46). A los protestantes se les permite, sin embargo, realizar sus encuentros en privado y adelantar labores educativas.

La segunda oleada la conforman misiones metodistas (movimiento surgido de la Iglesia Anglicana) y presbiterianas (denominación de la Iglesia Calvinista Escocesa), que llegan al país apoyadas por líderes liberales radicales, con los que compartían ideales sobre los efectos positivos de la educación en el camino hacia el progreso. En tanto se identifica con la necesidad de separar la Iglesia del Estado, así como de promover la educación libre y garantizar los derechos ciudadanos, este protestantismo se inscribe decididamente en un proyecto modernizador. En la práctica, tales demandas se traducen en un apoyo a reformas liberales que paulatinamente posibilitan, tanto en Colombia como en el resto de América Latina, la libertad de culto, el establecimiento del matrimonio civil, el uso de cementerios independientemente de la confesión y la expedición del registro civil desvinculado de la asignación parroquial. En este sentido, como apunta Bastian (2006), no se puede subestimar el papel político que este protestantismo desempeñó al desafiar las estructuras de poder tradicionales: "Las sociedades protestantes históricas, al igual que las logias masónicas, sirvieron como laboratorios donde se inculcaron nuevos valores que estaban en ruptura con los de la sociedad tradicional. Fueron laboratorios donde se fue creando el individuo ciudadano de la sociedad liberal y democrática”. (p. 42).

Pero los obstáculos para una expansión del protestantismo no habían desaparecido; por el contrario, se multiplicaron bajo los gobiernos conservadores en la época de la Regeneración. La evangelización y el trabajo en educación formal se vieron restringidos por la oposición de la jerarquía católica. La difusión más bien discreta de sus creencias se explica, además, por el hecho de que ella se realizaba fundamentalmente a través de la venta de Biblias y Nuevos Testamentos, con lo que se llegaba solo a sectores letrados, minoritarios en un país de mayorías analfabetas. De acuerdo con el censo de 1912, de los 5234598 habitantes, 4626669 no sabían leer ni escribir. De manera que aunque en principio el mensaje estuviera dirigido a todas las capas de la población, alcanzaba en realidad a "las clases medias, a intelectuales y liberales, escépticos y positivistas, librepensadores, estudiantes universitarios para quienes la figura del misionero resultaba atractiva por traer ideas de progreso, y como aliado en la lucha contra el clero" (Rodríguez, 2004, p. 305).

Sorteando obstáculos políticos y animosidades clericales, la labor educativa iniciada por los 
presbiterianos desde su arribo al país, cristaliza en la primera parte del siglo XX en la creación de los colegios americanos, orientados más hacia la formación moral e intelectual de ciudadanos que al proselitismo religioso. Fue en ellos, primero en Cali, en 1928, y posteriormente en Bogotá, donde se introdujo la educación mixta.

La tercera oleada de protestantismo que llegó a Colombia corresponde a misiones de fe evangelicalistas, impulsadas en los años veinte y treinta del siglo XX desde los Estados Unidos. Al mostrar con frecuencia una actitud anticatólica y al buscar la adhesión masiva de nuevos conversos -desertores de las filas del catolicismo-, generan animadversiones que se sumarán más tarde a los estereotipos corrientes durante la persecución que vivieron los protestantes desde finales de los años cuarenta (Ospina, 1954; Goff, 1965).

Aunque algunos misioneros pentecostales habían llegado años antes a Latinoamérica, la cuarta gran oleada tiene lugar en la posguerra y está representada por nuevas denominaciones pentecostales que se difunden, como describe Moreno (2010), "al son de las guitarras en reemplazo del piano y el órgano" (p. 23), poniendo énfasis en las manifestaciones del Espíritu Santo y en la sanidad de los enfermos. La expansión del pentecostalismo a mediados de siglo, está relacionada con las transformaciones sociales que produjeron en América Latina las grandes migraciones de campesinos hacia las ciudades en proceso de industrialización, situación a la que habría que agregar, en el caso específico colombiano, los desplazamientos ocasionados por la Violencia en zonas rurales. Bastian (2006) sostiene que los pentecostalismos, con sus rasgos de oralidad y emocionalidad, hicieron posible el surgimiento de vínculos que paliaron en las urbes la disolución de formas de vida tradicionales, y añade que, independientemente de su origen norteamericano, el pentecostalismo adquirió pronto en Latinoamérica un rostro propio al integrar la profecía, la sanación y el exorcismo en un entramando de religiosidad popular con prácticas afines. Al recurrir a una comunicación oral, llena de emocionalidad y cercana a elementos populares, el pentecostalismo se distancia claramente del protestantismo histórico, que se apoyaba en la palabra escrita y se mantenía alejado tanto de las formas como de los contenidos de la cultura popular. Bastian (2006) agrega que la pérdida de protagonismo político del protestantismo histórico a mediados de siglo coincide en varias regiones de América Latina con el crecimiento del pentecostalismo:

En los años cincuenta los protestantismos históricos eran un fenómeno religioso anecdótico, extremadamente marginal pues ni siquiera representaba el 1\% de la población de la región. Sobrevivían dentro de un contexto en el que los factores que habían sido necesarios para su expansión habían desaparecido. El liberalismo en particular estaba siendo transformado por nuevas perspectivas ideológicas, al lado del marxismo y de los movimientos revolucionarios de los años sesenta, que hicieron que el protestantismo no viviera un segundo período de enlace con aquellas ideologías nuevas que de hecho eran no solamente anticatólicas, sino también antirreligiosas y anticlericales". (p. 44)

La quinta oleada, la de los movimientos neopentecostales y carismáticos, ocurre a partir de los años setenta y está compuesta por iglesias independientes que mantienen pocos vínculos con las denominaciones tradicionales, presentan una visión del mundo como una gran guerra espiritual y articulan con frecuencia en sus prédicas una "teología de la prosperidad", del éxito económico como signo de bendición divina Su estilo de alabanza, los contenidos de sus prédicas y su perspectiva del papel de la iglesia en la sociedad penetra en adelante tanto en las iglesias pentecostales como en otras iglesias ya establecidas (Schäfer, 1992; Beltrán, 2005).

En la historia de Colombia, el periodo comprendido entre 1930 y 1946, conocido como la República Liberal, es favorable para el aumento de la feligresía protestante. Además de iglesias pentecostales como las Asambleas de Dios, y Cuadrangular, arriban otras denominaciones protestantes históricas como los menonitas, los luteranos y los bautistas. Esta proliferación es percibida por la Iglesia Católica como una amenaza, y desencadenará pronto persecuciones en 
regiones rurales (Ordóñez, 1956; De Bucana, 1995). Con el nuevo ascenso del gobierno conservador, la persecución se recrudecerá hacia finales de los cuarenta, alcanzando sus momentos más críticos entre 1948 y 1958, lapso en el que se cierran escuelas, se prohíbe la realización de cultos en los territorios misionales, se macartiza a los protestantes como grupo, se queman templos y, en consecuencia, se produce el desplazamiento de congregaciones enteras hacia las grandes ciudades. Que el fervor antiprotestante no solo se inoculaba desde los púlpitos católicos de provincia entre los sectores menos cultivados de la población, sino que se alentaba también desde la política centralista, es algo que se puede apreciar en el discurso de año nuevo del general Rojas Pinilla, en 1954:

Los protestantes están unidos con los comunistas para destruir la unidad nacional de Colombia... Como se desprende no sólo de la historia de la Reforma, sino de la experiencia cotidiana, la propaganda protestante en los pueblos latinos no conduce tanto al aumento del número de protestantes sinceros y respetables, sino a la pérdida de toda fe religiosa o el inevitable ingreso al comunismo de todos aquellos que han recibido enseñanzas fundamentalmente contrarias a dogmas esenciales del catolicismo". (citado por De Bucana, 1995, p. 131)

Los protestantes buscaron hacer frente a estos ataques creando una organización que visibilizara, nacional e internacionalmente, los atropellos que padecían y unificara sus voces para exigir del Estado el respeto y la protección de sus libertades. Es así como surge, a principios de los años cincuenta, la Confederación de Evangélicos de Colombia (Ce$\mathrm{dec}$ ), que cuenta entre su objetivos el "representar a las entidades [evangélicas] ante los poderes públicos y ante la opinión de los pueblos, en defensa de los derechos relacionados con la libertad de conciencia, de cultos, de enseñanza, etc." (citado por De Bucana, 1995, p. 160). La Confederación se declara además "ajena de cualquier movimiento político; se adhiere a toda doctrina política que protege la dignidad del hombre como criatura de Dios" (p. 160). A partir de este momento y durante tres décadas, se establece implícitamente un distanciamiento de lo político y de los compromisos sociales pues, como explica Moreno (2009), no solo se temía que "al enfatizar la responsabilidad social de la iglesia se podía dar lugar a una intromisión de ideas socialistas", como ocurría a la sazón en sectores del catolicismo afines a la teología de la liberación, sino que, en virtud de la escatología premilenarista que se había vuelto predominante, se consideraba la salvación del alma como algo urgente, que tenía prioridad sobre las necesidades del cuerpo. Curiosamente, el señalamiento de los protestantes como comunistas, afirmado por los conservadores en los años cincuenta, cederá su lugar un decenio después en los movimientos de izquierda de América Latina a una acusación opuesta, según la cual el protestantismo -para este momento identificado con el evangelismo pentecostalizado en ascenso- era un frente del imperialismo norteamericano (Bastian, 2006). Con todo, el distanciamiento de los protestantes colombianos frente a la acción política se mantendrá hasta principios de los años noventa, cuando deciden participar en la Asamblea Constituyente, en la cual logran elegir dos representantes. En las elecciones parlamentarias de 1992 alcanzan dos curules en el Senado y una en la Cámara. Desde entonces su participación política directa languidece, aunque su condición de potencial electoral se consolida.

\section{El estudio del protestantismo en la actualidad}

Desde la última década del siglo XX se han multiplicado en Colombia los estudios sobre diferentes aspectos del protestantismo. Para mencionar solo algunas, las investigaciones históricas de Moreno (2009, 2010), Bidegain (2004) y De Bucana (1995), que han enriquecido un campo en el que las referencias eran escasas, limitándose a unas pocas obras nacionales como las de Restrepo (1943) y Ordóñez (1956), o algunas monografías realizadas por estudiosos norteamericanos en los años sesenta y setenta (Goff, 1965; Butler 1976). Igualmente, estudios como los de Beltrán $(2010,2006)$ han actualizado el abordaje sociológico del protestantismo, en particular del pentecostalismo en la ciudad de Bogotá. También se han abierto caminos importantes con 
trabajos relacionados con el comportamiento político de agrupaciones evangélicas, como los realizados por Helmsdorf (1996) y Cepeda (2007). Estudios como estos se suman a investigaciones internacionales realizadas desde los años noventa (Stoll, 1993; Martin, 1993; Schäfer, 1992; Bastian, 1990), que describen dinámicas similares a nivel continental.

Conforme con el propósito del presente escrito de elaborar una panorámica de aspectos históricos, doctrinales e investigativos del protestantismo en general y de los movimientos pentecostales en particular, quisiera en lo que resta reseñar algunos elementos teóricos de su abordaje en los campos de la sociología y la psicología (reconocemos de paso cierta arbitrariedad al deja de lado otra dimensión básica: la antropológica).

En el análisis sociológico de religión en la actualidad podemos identificar dos puntos de partida, que muestran igualmente la influencia de la perspectiva weberiana: de una parte el que describe la pluralización de ofertas en un mercado religioso que se pone a tono con las decisiones subjetivas de consumo, cuestionando la pronosticada tendencia hacia la secularización y la privatización de lo religioso (Berger, Warner); de otra, el que describe la centralización del capital religioso en una institución que se ve desafiada en su administración monopólica con el surgimiento de nuevos productores y distribuidores de bienes espirituales (Bourdieu).

Con respecto al primero, mencionamos ya la pregunta por el carácter aparentemente inevitable e irreversible del proceso de secularización en el mundo occidental, asociado a una triunfante racionalización en la producción económica, en el control de la naturaleza, en la administración de la sociedad y en la formación de un ethos religioso que rechaza los medios sobrenaturales para obtener la salvación. Así como la autonomización de esferas de valor -economía, ciencia, política, ética- hace que las instituciones religiosas pierdan una parte considerable de su poder para configurar la vida social, el debilitamiento de estructuras comunitarias como ámbito de socialización y de reproducción de esquemas cognitivos compartidos, produce la erosión de la base social que hacía posible el man- tenimiento de creencias religiosas comunes (Berger, 1973). Si la separación de Iglesia y Estado elimina las adscripciones religiosas impositivas y relega la religión al ámbito de lo privado, la pluralización de formas de vida hace que ella aparezca cada vez más como un asunto de elección desde preferencias subjetivas a las que, a la manera de un mercado de bienes espirituales, buscan responder denominaciones en competencia. De cualquier forma, se preveía que tales búsquedas espirituales inquietarían cada vez a menos personas.

Aunque esta interpretación mantuvo por un tiempo cierto consenso académico, su validez general se puso en cuestión con la visible popularización de diferentes fenómenos religiosos en la última parte del siglo pasado. Para el caso específico de la persistencia o renovación de elementos religiosos tradicionales en los Estados Unidos, Stephen Warner (1993) propuso un "nuevo paradigma" que bien merece tomarse en cuenta como punto de referencia. $\mathrm{Su}$ propuesta interpretativa considera el hecho de que en los Estados Unidos las instituciones religiosas operan dentro de un mercado abierto, pluralista y estructuralmente flexible, y afirma que ellas llegan a convertirse en vehículo de empoderamiento para minorías subyugadas. La temprana desestimación de una religión oficial permitió a los ciudadanos ejercer la libertad de culto y obligó a las iglesias a movilizarse para mantener o ganar adeptos. En estas condiciones se ha establecido un mercado espiritual abierto, que más que desestimular la actividad y la movilidad religiosas, las revitaliza con la pluralización de las ofertas con las que los empresarios buscan satisfacer las necesidades de los consumidores.

Warner observa que la religión en los Estados Unidos ha sido constitutiva en la identidad subcultural y ha fungido como elemento asociativo. A las razones que han promovido históricamente la congregación -geografía, clase social, raza, procedencia nacional, generación, etnia e idioma- se suman hoy en día el género, la orientación sexual, los estilos de vida y la cultura moral. Por otra parte, las instituciones religiosas, al buscar responder a las demandas de los consumidores y a las iniciativas de los proveedores, han mantenido un grado de 
flexibilidad en la liturgia y en sus interpretaciones teológicas, lo que permite una mayor adaptabilidad a nuevas situaciones sociales, culturales y políticas. $\mathrm{Al}$ constituir un espacio en el que se combinan lo material y lo simbólico, se fortalece una moral de grupo y se crean redes sociales, las iglesias construyen un potencial latente de empoderamiento de individuos y grupos (minorías, mujeres). Pero la potencia especial de las instituciones religiosas, añade Warner, proviene de las respuestas que le dan a un grupo sobre lo justo de su causa y la inevitabilidad del triunfo. Esta fortaleza, que proviene de la creencia en una realidad penetrada por lo religioso, es algo que tradicionalmente han subestimando quienes parten de un supuesto racionalista, según el cual el pensamiento religioso representa siempre un obstáculo para la acción colectiva.

Finalmente, Warner señala la importancia del "voluntarismo", es decir, la afiliación individual a partir de la persuasión, más que en la coerción. Tal decisión representa el viraje de una membresía "expresiva colectiva" a una "expresiva individual", como parte de afirmación identitaria, lo cual permite entender el especial fervor que muestran los convertidos -ya tengan ellos tendencias liberales o conservadoras- frente a quienes han heredado su pertenencia religiosa.

Evidentemente, las condiciones en las que echa raíces históricamente este pluralismo son diferentes de la nuestras, pero algunos de los aspectos que señala Warner bien pueden considerarse en la descripción de funciones, cada vez más identificables, de las pertenencias religiosas en nuestro medio, en cuanto elección que afirma identidades y como forma de asociatividad en torno a elementos socioculturalares particulares. Igualmente, la segmentación de ofertas dirigidas a sectores diferenciados de la población, especialmente notoria en grupos neopentecostales, refleja dinámicas de un mercado en el que se busca satisfacer necesidades de clientelas específicas. Sin embargo, el pluralismo que se va asentando en nuestras sociedades latinoamericanas ha tenido que abrirse espacio en condiciones de resistencia y lucha frente al monopolio histórico de la Iglesia Católica. Esta tensión entre una institución que pretende ad- ministrar de manera exclusiva los bienes espirituales dentro de una sociedad, y grupos disidentes que logran poner en cuestión tal pretensión, queda mejor descrita en el segundo enfoque sociológico que queremos reseñar: la concepción de la religión como campo autónomo, formulada por Pierre Bourdieu.

Desde esta perspectiva se subraya el proceso a través del cual se constituyen instancias especializadas en la producción, reproducción y difusión de los bienes religiosos, un cuerpo de especialistas a los que socialmente se les reconoce una competencia legítima y exclusiva que posibilita la monopolización de los bienes de salvación, y frente a los que el resto de la sujetos se reconocen como profanos. En términos de Bourdieu (2006), las instancias religiosas poseen un capital religioso, que movilizan en su gestión de los bienes de salvación y en el ejercicio de un poder que les permite modificar, de manera duradera, tanto las representaciones como las prácticas de los laicos mediante la producción de un habitus, esto es, de un "principio generador de todos los pensamientos, percepciones y acciones, según las normas de una representación religiosa del mundo natural y sobrenatural, o sea, objetivamente ajustados a los principios de una visión política del mundo social" (p. 62).

De manera que la autonomía del campo religioso como mercado de bienes de salvación no desvincula a la religión de una función política; por el contrario, "la iglesia contribuye la mantenimiento del orden político y al reforzamiento simbólico de las divisiones de este orden" (p. 75). La religión así administrada desempeña una función ideológica: "función práctica y política de absolutización de lo relativo y de legitimación de lo arbitrario, que no puede cumplir sino en tanto asegure una función lógica y gnoseológica que consiste en reforzar la fuerza material o simbólica susceptible de ser movilizada por un grupo o una clase, legitimando todo lo que define socialmente a ese grupo o esa clase" (2006, p. 50).

La Iglesia es la institución que representa el monopolio del ejercicio legítimo del poder religioso y desde la cual se realiza la lucha contra la competencia de sectas e iglesias independientes, que desafían 
tal monopolio al satisfacer por sí mismos sus necesidades religiosas, sin la intermediación eclesiástica. El profeta aparece así como un "empresario independiente” en situación de acumulación inicial de capital religioso, un nuevo productor y distribuidor de bienes de salvación y, en ese sentido, como un adversario. Lo que ha fallado en este caso es la aptitud de la institución que detenta la autoridad religiosa para hacer reconocer, a los que están excluidos de ella, "la legitimidad de su exclusión i.e. para hacerles desconocer lo arbitrario de la monopolización de un poder" (p. 66). En el caso histórico de la Iglesia Católica, tal pérdida de legitimidad queda plasmada en el triunfo de los principios del sacerdocio universal y del libre examen de la Escritura.

Estos dos enfoques son, sin duda, referentes para abordar un aspecto importante del desarrollo del protestantismo en Colombia y América Latina. Pero una comprensión más precisa de este fenómeno nos exige considerar al menos otra dimensión de lo religioso, relacionada ya no con sus funciones o dinámicas sociales, sino con sus aspectos psicológicos. En este sentido, notamos en la creciente literatura sobre el protestantismo y los movimientos pentecostales en nuestro país la ausencia de estudios realizados desde una perspectiva psicológica, lo que parece indicar que en la actualidad el fenómeno despierta poco interés en una disciplina que históricamente hizo importantes elaboraciones en el campo de la religión, desde que este dejó de ser objeto exclusivo de la teología y la filosofía para abordarse desde perspectivas naturalistas. Concluiremos entonces este recorrido presentando algunos aspectos del estudio contemporáneo del pentecostalismo en la psicología.

En general, las posiciones sobre la religión en la psicología pueden colegirse ya de las apreciaciones de tres grandes clásicos: James, Freud y Jung. James (2002) considera la religión como una experiencia individual de carácter trascendente, una relación que con sus sentimientos, actos y experiencias establecen los individuos con la entidad que consideran divina. Sin afirmar que ella sea en sí algo negativo y más bien apreciando su utilidad como medio de adaptación social, James distingue entre la religión de la mente sana, tal como se manifiesta en las personas optimistas que ven lo bueno en el mundo, sin sentir la necesidad de renacer en otro estado de cosas o mudar en un nuevo estado de consciencia, y la religión del alma enferma, propia de quienes perciben permanentemente la presencia del mal y buscan la redención y el renacimiento. Freud (1970), por su parte, es más categórico al considerar la religión en lo fundamental como expresión de un sentimiento infantil de indefensión, proyectado en la ilusión de un padre protector, omnipotente y omnisciente. Desde el punto de vista práctico, esta ilusión permite suponer orden en un mundo que, de lo contrario, perdería su sentido, y tiene además efectos civilizatorios, al contribuir al control individual de los deseos antisociales. Pero no por ello deja de representar un estado de dependencia infantil, una incapacidad de aceptar la realidad de la fragilidad humana. Jung (2011), por el contrario, no ve la religión como una neurosis, sino como algo más bien saludable psíquicamente a partir de cierto momento de la vida. Dios deja de ser la proyección de algunos individuos ante fuerzas que lo aterrorizan, para convertirse en un arquetipo heredado colectivamente que toma la forma de una entidad específica en diferentes épocas y culturas.

En relación con nuestro tema específico, señalaremos que esta diferencia en la apreciación del fenómeno religioso aflora también en los estudios sobre el pentecostalismo a lo largo del siglo XX, en el que es posible identificar claramente dos períodos (Huber y Huber, 2010): uno "hostil", que anima los estudios tempranos sobre el movimiento ya en los años veinte, y un período "amigable" que comienza en los años sesenta, en un viraje que nos ofrece, por cierto, un ilustrativo ejemplo de la manera en que los valores del observador permean la interpretación de su objeto. En la primera etapa, los investigadores partían del supuesto de que el pentecostalismo reflejaba "procesos psicológicos anormales y desórdenes mentales", y establecían, correspondientemente, un marco psicopatológico de interpretación basado en los conceptos de esquizofrenia, histeria, regresión, inestabilidad emocional, inmadurez, neurosis o dogmatismo, que asociaban además con situaciones 
de pobreza. Como ejemplo de esta visión mencionan Huber y Huber la obra Speaking with Tongues: Historically and Psychologically Considered, de George B. Cutten (1927), en la que se describe la glosolalia como una reacción infantil relacionada con una baja educación: "Quienes hablan en lenguas son casi sin excepción gente devota, pero ignorante e iletrada" (citado por Huber y Huber, 2010, p. 136).

Por el contrario, en la etapa "amigable" los estudios se centran más en características de la personalidad normal y consideran indicadores de estabilidad psicológica, o estudian relaciones positivas de la vivencia religiosa con el bienestar físico (efectos sobre recuperación de una enfermedad, aumento en las expectativas de vida). Se trata de investigaciones que subsanan deficiencias metodológicas de la primera etapa, tienen una mejor base teológica y son más interdisciplinarias. Esta perspectiva la ilustrarían estudios como The Personality Characteristics of Pentecostal Ministry Candidates, de Francis y Key (1995), quienes emplean el modelo de personalidad de Eysenck para evaluar rasgos de personalidad de 205 candidatos y 105 candidatas al ministerio pentecostal, y concluyen que tanto hombres como mujeres de este grupo se ubican por debajo de la media de la población en neuroticismo; que solo los hombres están por debajo de la media en psicoticismo; y que ni hombres ni mujeres difieren en la puntuación de extroversión con respecto al resto de la población.

También la glosolalia deja de enfocarse desde la anormalidad y se explica, ya sea en el contexto del trance provocado por una sobreestimulación cortical a través de las palmas rítmicas, el éxtasis del canto y la oración y los movimientos corporales repentinos (Goodman, 1969), ya como comportamiento socialmente aprendido, esto es, como una "competencia" que los individuos pueden activar a voluntad (Spanos, 1979). El uso de técnicas de neuroimagen para determinar patrones de actividad cerebral relacionados con el habla en lenguas (Newberg, 2006), ha ofrecido resultados consistentes con la hipótesis del trance (las tres referencias son tomadas de Huber y Huber, 2010).
Cuestionando la insuficiencia de los estudios que se elaboran en torno a conceptos como ansiedad, sugestionabilidad, dependencia, liberación emocional, regresión, estabilidad emocional, extroversión, autocontrol, depresión, hostilidad, autoestima, etc., por considerar que mantienen una perspectiva externa a la religiosidad pentecostal, a la que toman como una "caja negra" al vaivén de determinaciones exógenas, Huber y Huber proponen que estos se complementen con una mirada dirigida a las estructuras y dinámicas endógenas de la vivencia religiosa específica. Para tal fin adoptan el modelo sociológico multidimensional de la religiosidad propuesto por Glock y Stark (1962), complementándolo en dimensiones psicológicas y teológicas. El modelo resultante considera cinco dimensiones básicas de la religiosidad (pp. 143 y ss.):

Dimensión intelectual: referida al conocimiento que se tiene sobre la fe religiosa particular, una religious literacy que involucra, de una parte, la competencia para jugar con símbolos religiosos y construir activamente una teología subjetiva personal, y de otra, la competencia para transferir el vocabulario y la gramática de la religión a situaciones específicas de la vida cotidiana.

Dimensión ideológica: constituida por las creencias que abriga la persona (p.e, su concepción de Dios) y que orientan sus evaluaciones y actitudes éticas o políticas.

Dimensión experiencial: referida al contacto directo que establezca la persona con una realidad última, sobrenatural.

Dimensión de la práctica religiosa privada: que abarca los hábitos de oración y lectura.

Dimensión de la práctica religiosa pública: referida a la integración de la persona en una red social, a partir de hábitos como el de la asistencia a una iglesia.

El carácter general de esta propuesta permite considerarla como una prometedora orientación para ampliar el estudio de los movimientos protestantes contemporáneos en nuestro país. Las dimensiones que propone bien pueden tomarse como punto de partida para una exploración en la constitución de nuevas subjetividades religiosas. 


\section{Conclusiones}

La tesis de un irreversible declive de la religión, como consecuencia del triunfo de la racionalidad moderna occidental, se pone en cuestión en las postrimerías del siglo XX con el fortalecimiento de movimientos religiosos. En América Latina, el mayor de ellos lo constituyen las agrupaciones pentecostales.

Hasta su abolición, en 1823, el Tribunal de la Santa Inquisición impidió el asentamiento del protestantismo en Colombia. Solo tras los movimientos de independencia y con la difusión de las ideas liberales, la fe protestante empieza a tener un reconocimiento, que sin embargo avanza y retrocede según los climas políticos, sin consolidarse hasta el último cuarto del siglo XX.

La primera iglesia protestante en Colombia es la presbiteriana, que dio impulsos modernizantes a la educación. Otros protestantismos históricos (luteranos, bautistas) arriban al país apenas en los años cuarenta del siglo XX.

El protagonismo social y político de los protestantismos históricos, de rasgos liberales y progresistas, decrece a partir de los años cincuenta. Esto coincide con el ascenso de los movimientos pentecostales, que reintroducen en sus doctrinas y sus prácticas elementos mágicos y emocionales rechazados tempranamente por los protestantes históricos.

A partir de los años sesenta ganan popularidad en toda América los movimientos neopentecostales y carismáticos, que mostrarán en adelante un amplia utilización de tecnologías electrónicas tanto en sus celebraciones como en la difusión de sus mensajes. En lo doctrinal promueven una teología de la prosperidad.

A pesar de su procedencia, el protestantismo que se establece en Latinoamérica no es una transposición mecánica de creencias foráneas, sino que lleva a cabo una apropiación y resignificación de elementos importados en los contextos culturales propios. Las iglesias se nacionalizan, no solo en el sentido administrativo, sino también en un sentido cultural.

En parte debido a la adopción de una concepción premilenarista de la historia entre las agrupaciones evangelicales y pentecostales, y en parte por las presiones y persecuciones durante la Violencia, los protestantes se marginan de la vida política desde finales de los años cincuenta hasta 1990, cuando participan en la Asamblea Constituyente.

Las investigaciones en ciencias sociales sobre el protestantismo en Colombia han florecido en lo últimos dos decenios, sobre todo en los campos de la historia y la sociología. En esta última, el paradigma de la secularización se desplaza por una interpretación de la pluralización como diversificación de la oferta en un mercado religioso. En cuanto a la psicología no se aprecia un interés importante, a pesar de la existencia de nuevos enfoques que abandonan una visión "patologizante" para abordar la complejidad de la vivencia religiosa.

\section{Referencias}

Alexander, P. (2009). Signs and Wonders. Why Pentecostalism is the World's Fastest-growing Faith. San Francisco: Jossey Bass.

Anderson, A. (1999). The Gospel and Culture in Pentecostal Mission in the Third World. Ponencia presentada en la 9a. Conferencia de la European Pentecostal Charismatic Research Association. Documento en línea. Recuperado en febrero de 2012. Disponible en: http://artsweb.bham.ac.uk/aanderson/Publications/ pentecostal_gospel_htm

Barrett, D. (1982). World Christian Encyclopedia. Nueva York: Oxford University Press.

Balmer, R. (2004). Encyclopedia of Evangelicalism. Waco: Baylor University Press.

Bastian, J. (1990). Historia del protestantismo en América Latina. México: CUPSA.

Bastian, J. (2005). Pentecostalismos latinoamericanos. Lógicas de mercado y transnacionalización religiosa. En A. Bidegain y J. Demera (Comps.), Globalización $y$ diversidad religiosa en Colombia (pp. 323-341). Bogotá: Universidad Nacional de Colombia.

Bastian, J. (2006). De los protestantismos históricos a los pentecostalismos latinoamericanos: análisis de una mutación religiosa. En Revista de Ciencias Sociales, $16,38-54$.

BBC Mundo. (2007). ABC de los evangélicos en América Latina. Documento en línea. Publicado el 3 de mayo de 2007. Disponible en http://news.bbc.co.uk/ 
hi/spanish/specials/2007/en_nombre_de_la_fe/ newsid_6620000/6620237.stm

Beltrán, W. (2005). La diversificación del cristianismo en Bogotá. En A. Bidegain y J. Demera (Comps.), Globalización y diversidad religiosa en Colombia (pp. 257291). Bogotá: Universidad Nacional de Colombia.

Beltrán, W. (2006). De microempresas religiosas a multinacionales de la fe. La diversificación del cristianismo en Bogotá. Bogotá: Bonaventuriana.

Beltrán, W. (2010). La teoría del mercado en el estudio de la pluralización religiosa. En Revista colombiana de sociología, 33 (2), 41-62.

Berger, P. (1973). The Social Reality of Religion. Middlesex: Penguin.

Berger, P. (1996). Secularism in retreat. In The National Interest, 46, 3-12.

Bidegain, A. (Dir.). (2004). Historia del cristianismo en Colombia. Corrientes y diversidad. Bogotá: Taurus.

Bourdieu, P. (2006). Génesis y estructura del campo religioso. En Relaciones - Estudios de historia y sociedad, Vol. XXVII (108), 29-83.

Butler, F. (1976). Protestantism in Colombia: Baptism by Fire and Spirit. London: Associated University Press.

Castaño, E. (2012). Entrevista personal del autor con el Presidente de Cedecol. Bogotá, febrero.

Cepeda, A. (2007). Clientelismo y fe: dinámicas políticas del pentecostalismo en Colombia. Bogotá: Bonaventuriana.

Dawkins, R. (2006). The God Delusion. London: Bantam Press.

De Bucana, J. (1995). La iglesia evangélica en Colombia. Una historia. Bogotá: Asociación Pro-Cruzada Mundial.

El Tiempo. (2011). Una de cada cuatro iglesias en Colombia no es católica. Bogotá, mayo 22.

Freud, S. (1970). El porvenir de una ilusión. Madrid: Alianza.

Goff, J. (1965). The Persecution of Protestant Christians in Colombia 1948-1958. San Francisco Seminary.

Habermas, J. (2005). Zwischen Naturalismus und Religion. Frankfurt am Main: Suhrkamp.

Helmsdorf, D. (1996). Participación política evangélica en Colombia (1990-1994). En Historia crítica, 12, 79-84. Bogotá: Universidad de los Andes.

Hernández, D. y Forero, E. (2005). Una historia que no termina. Medellín: Buena Semilla.
Huber, S. \& Huber, O. (2010). Psychology of Religion. En A. Anderson, M. Bergunder, A. Droogers \& C. van der Laan (Eds.), Studying Global Pentecostalism. Berkeley: University of California.

James, W. (2002). Varieties of Religious Experience. A Study in Human Nature. New York: Routledge.

Jung, C. (2011). Psicología y religión. Barcelona: Paidós.

Kasper, W. (2007). Ökumene vor neuen Herausforderungen. Documento en línea. Recuperado en febrero de 2012. Disponible en http://www.kardinal-kasperstiftung.de/Vortrag_oekumenepreis.html\#jenkins

Koester, R. (s.f.). The Pentecostal and Charismatic Movement. Wisconsin Lutheran Seminary Library. Documento en línea. Recuperado en febrero de 2012. Disponible en http://www.wlsessays.net/files/ KoesterPentecostal.pdf

Martin, D. (1993). Tongues of Fire: The Explosion of Protestantism in Latin America. Oxford: Blackwell.

Marx, K. (1968). Crítica a la crítica de la filosofía del derecho de Hegel. Buenos Aires: Claridad.

Moreno, P. (2007). La subjetividad de los sujetos. Desafío a la teología en América Latina. En Theologica Xaveriana, Vol. 57 (163), 471-484.

Moreno, P. (2009). La acción social de las Iglesias evangélicas en Colombia. Bogotá: Cedecol.

Moreno, P. (2010). Por momentos hacia atrás... por momentos hacia adelante. Una historia del protestantismo en Colombia 1825-1945. Cali: Bonaventuriana.

Ordóñez, F. (1956). Historia del cristianismo evangélico en Colombia. Medellín: Tipografía Unión.

Ospina, E. (1954). Las sectas protestantes en Colombia. Breve reseña histórica con un estudio especial de la llamada "persecución religiosa". Bogotá: Imprenta Nacional.

Restrepo, E. (1943). Historia del protestantismo en Colombia. Bogotá: Universidad Javeriana.

Rodríguez, J. (2004). Primeros intentos de establecimiento del protestantismo en Colombia. En A. Bidegain (Dir.), Historia del cristianismo en Colombia. Corrientes $y$ diversidad. Bogotá: Taurus.

Schäfer, H. (1992). Protestantismus in Zentralamerika. Frankfurt am Main: Peter Lang.

Stoll, D. (1993). ¿América Latina se vuelve protestante? Quito: Abya Yala.

Synan, V. (1997). The Holiness-Pentecostal Tradition. Grand Rapids, MI: William B. Eerdmans. 
Protestantes, evangélicos y pentecostales: aclaraciones conceptuales preliminares en un campode investigación social

Wallace, A. (1966). Religion: An Anthropological View. New York: Random House.

Warner, S. (1993). Work in Progress Toward a New Paradigm for the Sociological Study of Religion in the United States. In American Journal of Sociology, Vol. 98 (5), 1044-1093.

Weber, M. (1969). La ética protestante y el espíritu del capitalismo. Barcelona: Península.

Weber, M. (1977). Economía y sociedad. México: FCE. 